\title{
An elderly lady with an inspiratory stridor
}

\author{
A. Matthes ${ }^{1}$, R. Breumelhof ${ }^{2}$, E. van Beeck Calkoen ${ }^{3}$, K.J . van Everdingen ${ }^{4}$, L.E.M. Haas ${ }^{1}$ \\ 1. Department of I ntensive Care, the Diakonessenhuis, Utrecht, The Netherlands. 2. Department of Gastroenterology and \\ Hepatology, the Diakonessenhuis, Utrecht, The Netherlands. 3. Department of Otorhinolaryngology, the Diakonessenhuis, \\ Utrecht, The Netherlands. 4. Department of Radiology, the Diakonessenhuis, Utrecht, The Netherlands.
}

Correspondence: Lenneke E M Haas. Address: Department of Intensive Care, the Diakonessenhuis, Utrecht, The Netherlands. Email: Ivlelyveld@diakhuis.nl

Received: July 15, 2014

DOI : $10.5430 /$ crim.v2n1p39
Accepted: September 30, $2014 \quad$ Online Published: October 14, 2014

URL: http://dx.doi.org/10.5430/crim.v2n1p39

\section{Abstract}

An 87-year-old lady, known with Alzheimer's disease presented to the Emergency Department with dyspnea and an inspiratory stridor. As a consequence of her cognitive impairment, she was not able to provide a history and the diagnosis was not immediately clear. Laboratory examination showed a leucocytosis with an increased percentage of neutrophils and an elevated C-reactive protein. The chest radiography demonstrated a radiopaque object. She was admitted to the intensive care unit and an urgent endoscopy was performed. The stridor turned out to be due to ingestion of a button.

\section{Keywords}

Stridor, Foreign body aspiration, Elderly, Critical care, Pneumonia

\section{I ntroduction}

Adults regularly present to the Emergency Department with dyspnea, but stridor is a less commonly encountered presenting symptom in adults. A patient with a stridor requires prompt evaluation, since a stridor is usually caused by upper airway narrowing and partial obstruction.

History is very important in reaching the diagnosis, but can be impaired in some cases, like in the cognitively impaired patient. In this case we describe a cognitively impaired old lady who presented to our Emergency Department with an inspiratory stridor.

\section{Case report}

An 87-year old woman presented to our Emergency Department (ED) because of progressive dyspnea and an inspiratory stridor over the preceding few hours. She was known with Alzheimer's disease for ten years and as a consequence communication was very limited. The information that her family and caregivers could provide was also scarce. She was reported to have had a sore throat during the preceding week, however no choking episode was apparent. Physical examination revealed an elderly lady without fever, tachypneic (30 breaths per minute) with the aforementioned inspiratory stridor. Oxygen saturation was $95 \%$ with 4 litres of supplemental oxygen. Chest examination revealed bilateral audible rales and examination of the oral cavity and upper airways was considered normal at that moment. Laboratory 
examination showed an elevated C-reactive protein (CRP) $(104 \mathrm{mg} / \mathrm{L} ;<10 \mathrm{mg} / \mathrm{L})$ and leucocytosis $\left(13.2 \times 10^{9} / \mathrm{L} ; 4.0-10.0\right.$ $\times 10^{9} / \mathrm{L}$ with neutrophils $11.5 \times 10^{9} / \mathrm{L} ; 1.3-5.7 \times 10^{9} / \mathrm{L}$ ) among others. Chest radiography (CXR) demonstrated a radiopaque foreign body (see Figure 1).

Since the patient was symptomatic, an urgent endoscopy was performed. We were unable to remove the foreign body with the retrieval net, but with a laryngoscope and a Magill stylet, it was easily removed and it turned out to be one of the buttons of her jacket (see Figure 2).

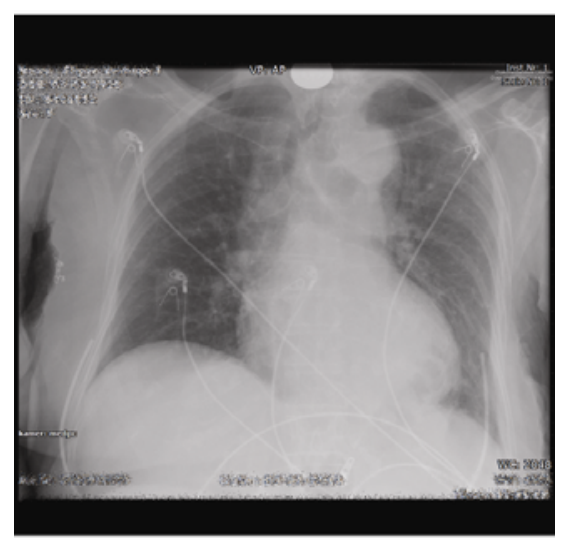

Figure 1. Chest $\mathrm{X}$-ray showing a radiopaque foreign body at the level of the trachea

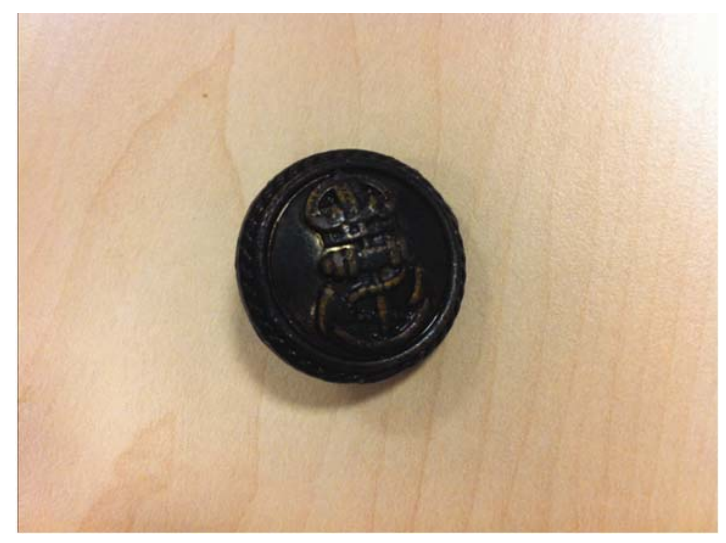

Figure 2. Photo of the removed foreign body: a button of her jacket

\section{Discussion}

Accidental foreign body ingestion or aspiration occurs primarily in children and in edentulous or mentally impaired elderly subjects. Age under 15 years and over 75 years, neurologic disorders, alcohol and/or sedative abuse and loss of consciousness are all risk factors ${ }^{[1]}$. In children, mentally impaired adults, and patients with psychiatric illness, history can be impaired and the diagnosis may be suspected by the associated symptoms, including dysphagia, dyspnea, fever, chest pain or wheeze, inability to swallow saliva, or in the presence of a radiopaque foreign body as illustrated by our case ${ }^{[2]}$. Computed tomographic scanning may be helpful if plain radiographs are negative. In patients with persistent symptoms, an endoscopic evaluation should be performed, even if the radiographic examination is negative ${ }^{[3]}$.

Due to the lack of an accurate examination of the upper airways, the diagnosis in our case was made only during a second step test (CXR). In conclusion, it is important to consider ingestion or aspiration of a foreign body in every patient that present with dyspnea and/or a stridor, especially in children and the elderly with cognitive impairment. The diagnosis is frequently overlooked.

In contrast to an ingested foreign body, which passed in the majority of cases and only requires endoscopic or surgical intervention in selected cases, an inhaled foreign body can migrate distally and needs intervention. Extraction can mostly be performed with flexible or rigid bronchoscopy, surgery is rarely necessary.

\section{References}

[1] Limper AH, Prakash UB. Tracheobronchial foreign bodies in adults. Ann Intern Med. 1990; 112(8): 604-609. PMid:2327678 http://dx.doi.org/10.7326/0003-4819-112-8-604

[2] Rafanan AL, Mehta AC. Adult airway foreign body removal. What’s new? Clin Chest Med. 2001; 22(2): 319-330. http://dx.doi.org/10.1016/S0272-5231(05)70046-0

[3] Swanson KL, Edell ES. Tracheobronchial foreign bodies. Chest Surg Clin N Am. 2001; 11(4): 861-72. PMid:11780300 